\title{
Partitioned Topologies of Switched Flux Permanent Magnet Machines for Electric Vehicles
}

\author{
Mahmoud S. R. Saeed \\ Department of Electrical Engineering, \\ Faculty of Engineering, South Valley University, \\ Qena, Egypt
}

\begin{abstract}
Partitioned Stator (PS) and Partitioned Rotor (PR) Switched Flux Permanent Magnet (SFPM) machines have the advantages of high torque density and high torque per PM volume compared with conventional SFPM machine. These advantages are considered important potentials for Electric Vehicles. This paper aims to provide a comparative study between recent PS and PR topologies using 2D Finite Element Analysis (FEA) modeling software. Two recent topologies of PS-SFPM machine, namely the Cylindrical Inner Stator (CY) and the Salient Inner Stator (SA), are compared with the topologies of PR-SFPM machine, namely the Parallel magnetic circuit (PA) and the Serial magnetic circuit (SE) PRSFPM machines. To have a fair comparative study, all these topologies have the same main dimensions and the same PM volume. Also, they have been optimized under the same conditions using FEA optimization tool. It is found that the PA PR topology has the best torque performance, in the meantime, the PS topologies have higher power density, and better flux-weakening capability.
\end{abstract}

\section{General Terms}

Finite element analysis, Modeling of electrical machine.

\section{Keywords}

Electric Vehicles, Switched flux PM, Partitioned rotor, Partitioned stator.

\section{INTRODUCTION}

Environmental pollution and global warming are considered the most critical fears in the recent years, which in turn motivate many countries to replace conventional gasoline vehicles with a new fuel cell, electric vehicles (EVs), or hybrid electric vehicles (HEVs) [1]. Thus, many research projects have focused on increasing the efficiency of the hybrid/electric vehicle. PM electric motors are one of the most interesting research topics in electric traction since they have high power density [2].

Switched flux permanent magnet (SFPM) machines have a great interest in the recent years since they have strong potentials for many applications such as; wind power generation, electric and hybrid vehicles, aerospace applications...etc. Hence, large number of advanced topologies of SFPM machine have been investigated in the recent years, for instance Partitioned Stator (PS) SFPM [3-5], Partitioned Rotor (PR) SFPM [6, 7], and Dual Rotor SFPM [8].

PS-SFPM topology was first introduced in [3]. The design principle of PS machines depends on combining two different machine design scenarios, i.e. switched flux and magnetic gears. The major idea of PS topology is the separation between the PMs and the armature windings, see Fig. 1(a). The PMs are placed in the inner stator, while the armature

\author{
Essam E. M. Mohamed \\ Department of Electrical Engineering, \\ Faculty of Engineering, South Valley University, \\ Qena, Egypt
}

windings are accommodated in the outer stator slots. The advantages of this topology are high power density, enhanced PMs cooling properties, and high torque per PMs volume ratio.

A great interest has been given to the PS-SFPM topology due to its advantages, which led to the emerge of many different forms of PS-SFPM machines. Hybrid-excited and wound field PS-SF machines have been investigated in $[9,10]$, respectively, to enhance the flux regulation capability and reduce the total cost. In [11], two different axial flux PSswitched flux machines with PM and wound field have been investigated, which showed more robust structure, enhanced thermal operation, and easier fabrication procedure. A PSSFPM with salient inner stator (SA) has been introduced by [4], which has the same performance of cylindrical inner stator (CY) PS machine with reduced weight and cost. The SA PS topology is shown in Fig.1(b).

On the other hand, the PR topology was first introduced as a single-phase DC-excited generator with parallel magnetic circuit, which is used in the rooftop wind power generation [12]. There are two types of PR machines; the parallel magnetic circuit (PA) PR, and the serial magnetic circuit (SE) $\mathrm{PR}$ as shown in Fig.2(a) and (b) respectively [6, 13].

This paper aims to provide a comparative study between PSSFPM and PR-SFPM topologies. To assure fair comparison, these machines were designed with the same main dimensions, i.e. axial length, outer radius, number of poles, and coils number of turns. Then they are optimized for maximum average torque and minimum torque ripples. In this study, four different topologies namely, CY PS-SFPM, SA PS-SFPM, PA PR-SFPM, and SE PR-SFPM machines, are compared. Section II illustrates the principles of operation of the four machine topologies. The optimization conditions and goals for the four studied topologies are illustrated in Section III. Section IV provides the electromagnetic performance results of all studied topologies, which are obtained from the FEA models. Section V provides the conclusions.

\section{OPERATION PRINCIPLES}

The idea of PS-SFPM machines depends on the separation between PMs and the armature windings. This can be done by replacing the rotor of conventional SFPM by a second stator, which accommodates the PMs. Hence, the rotor iron segments (poles) combined with a non-magnetic cylindrical holder are rotating between the two stators thanks to two air-gaps. The outer stator in PS-SFPM topology is the same as that of conventional SFPM machine with PMs removed [3]. The separation between the armature windings and the PMs results in two main advantages; first it eliminates the conflict between copper, PMs, and iron volumes, hence improved torque density can be achieved. Second, it provides better 
PMs cooling properties, since PMs are located on a separate stator.

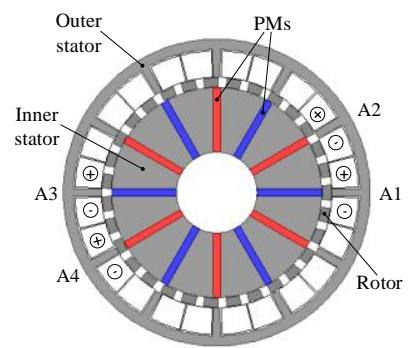

a) CY PS-SFPM

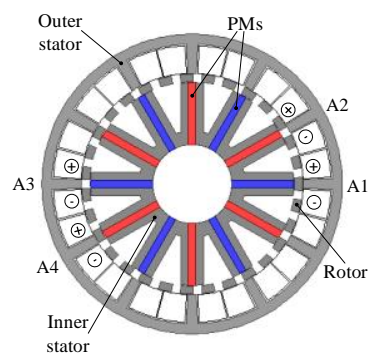

b) SA PS-SFPM

Fig.1 PS-SFPM machine topologies

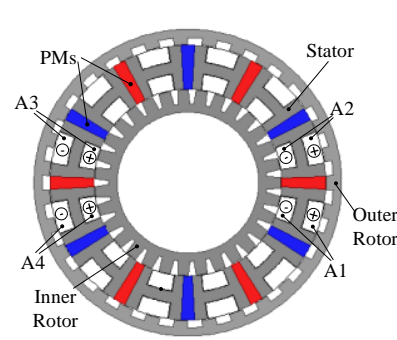

c) PA PR-SFPM

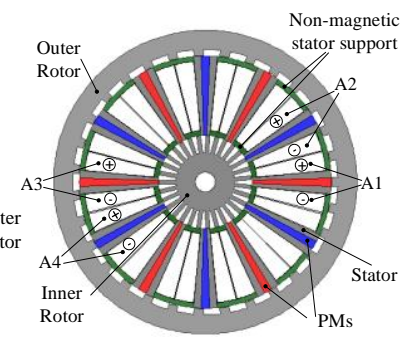

d) SE PR-SFPM
Fig.2 PR-SFPM machine topologies

Cylindrical Inner stator (CY PS-SFPM), as shown in Fig.1 (a), has an inner stator that allocates the PMs circumferentially. However, it is found that for high number of poles applications, not all the iron volume in the inner stator is needed. The PS-SFPM topology with salient inner stator (SA PS-SFPM) was proposed, which has the same performance, but with reduced weight and cost [4]. The principles of operation of CY PS-SFPM and SA PS-SFPM machines are the same, as shown in Fig.3. When the rotor moves, the reluctance between both stators changes. Therefore, the flux linkage to the armature windings varies with rotor position, which results in the flux-switch effect.

The main parts of the PR-SFPM topology are one stator sandwiched between two portions of the rotor. The rotor portions are combined with an end disk to have the torque summation of both portions at the same speed. Since the rotor is divided into two parts, PR-SFPM topology has high power density and improved PM utilization [6]. In contrast to PSSFPM topology, the stator of PR-SFPM topology accommodates the PMs and the armature windings. Therefore, PR topologies have reduced PMs cooling property compared with PS topologies.

There are two different topologies of PR-SFPM machines; namely parallel magnetic circuit (PA) PR-SFPM, and serial magnetic circuit (SE) PR-SFPM. In PA PR topology the stator has the PMs sandwiched between laminated ' $H$ ' shaped iron cores, and toroidal wound concentrated armature windings. On the other hand, the SE PR-SFPM topology has a yokeless stator with the PMs sandwiched between 'I' shaped laminated iron cores with concentrated armature windings. In this topology, a non-magnetic support is needed to join the stator iron cores together.

The operating principles of PA PR-SFPM machine are shown in Fig. 4(a). The PA PR-SFPM topology may be considered as two SFPM machines with common stator yoke. Hence, there are two separate parallel flux paths in the stator yoke. The flux in the stator yoke varies with the rotor position. Hence the flux-switch effect is also applicable on PA PR SFPM topology. On the other side, SE PR-SFPM topology has a single serial flux path between the inner and the outer rotor parts passing through the stator tooth, as shown in Fig. 4(b). It is clear, from Fig. 4(b), that the inner rotor portion is shifted by half of the rotor pole pitch with respect to the outer rotor portion to complete the flux path. When the rotor moves, the flux linkage alternates between maximum negative and positive values.
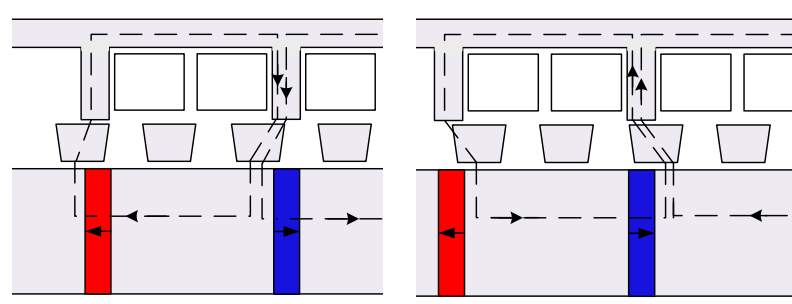

(a) CY PS-SFPM machine
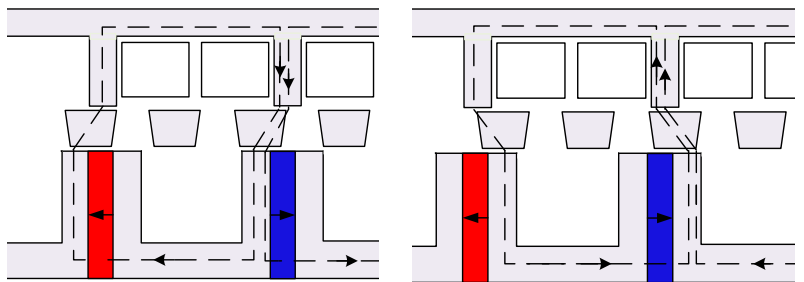

(b) SA PS-SFPM machine

Fig.3 Operating principles of PS-SFPM topologies

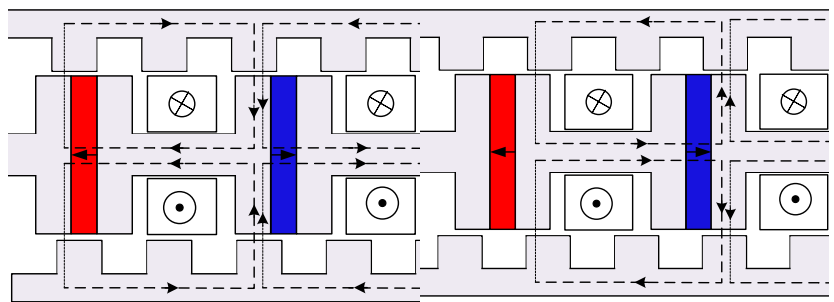

(a) PA PR-SFPM machine

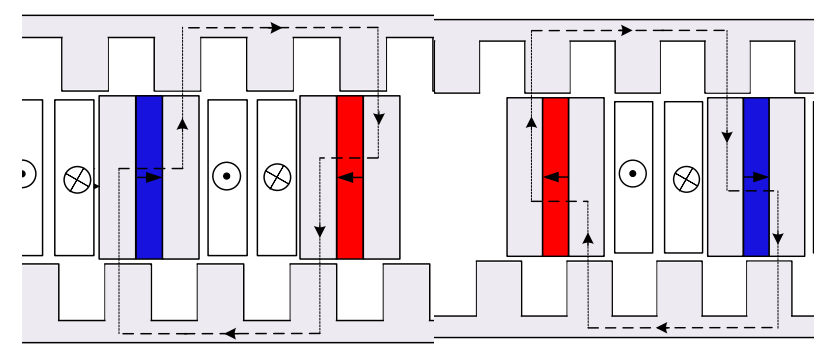

(b) SE PR-SFPM machine

Fig.4 Operating principles of PR-SFPM topologies

\section{RESEARCH METHOD}

This paper aims to compare between the partitioned topologies of SFPM machines for EVs. To guarantee fair compare, the main design parameters, i.e. the outer diameter, number of poles, axial length, and number of turns of the armature windings are maintained the same for all topologies. The other design parameters are optimized to achieve the maximum average torque and minimum torque ripples. The optimization tool of ANSYS Maxwell software is used for multi-objective optimization of all topologies under the same conditions. The objective and cost functions are calculated according to ANSYS Maxwell user manual as follows; 


$$
\begin{gathered}
\mathrm{G}_{1}=1+\left(100-\mathrm{T}_{\text {ave }}\right) \times(9 / 20) \\
\mathrm{G}_{2}=1+\left(\mathrm{T}_{\mathrm{rp}}-0.5\right) \times(9 / 9.5) \\
\text { cost }=1 \times\left(\mathrm{G}_{1}-1\right)^{2}+1 \times\left(\mathrm{G}_{2}-1\right)^{2}
\end{gathered}
$$

where $\mathrm{T}_{\mathrm{ave}}$ is the average output torque, and $\mathrm{T}_{\mathrm{rp}}$ is the peakto-peak torque ripple. It is important to maintain same PM volume in all topologies during the optimization process, thus the PM width (or arc) is calculated as a function of the PM length to maintain same PM area. The design parameters are illustrated in Fig.5 and the optimal value for each parameter is given in Table. I. It should be noticed, from Table. I, that the common parameters between all topologies are maintained constant. High stator/rotor pole combination (12/31) are selected for all topologies to fit the direct drive application.

\section{RESULTS AND ANALYSIS}

The direct drive motors should have some important specifications; such as high-torque density, high PM utilization ratio, high efficiency, and wide speed control range with constant power $[14,15]$. In this section, the performances of the studied topologies are investigated and compared, based on the time stepping FEA method, at different cases. The studied topologies have the same potentials and conditions in order to make a fair judgment.

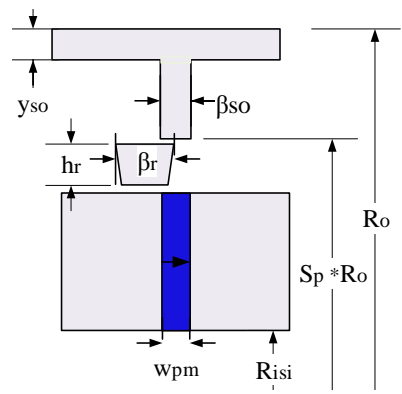

(a) Cy PS-SFPM

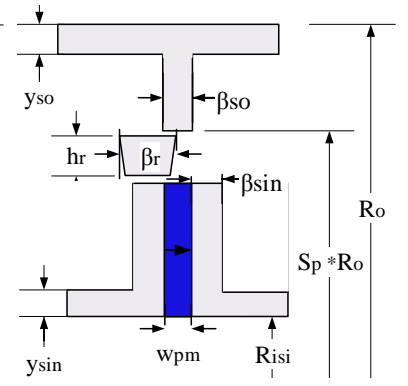

(b) SA PS-SFPM
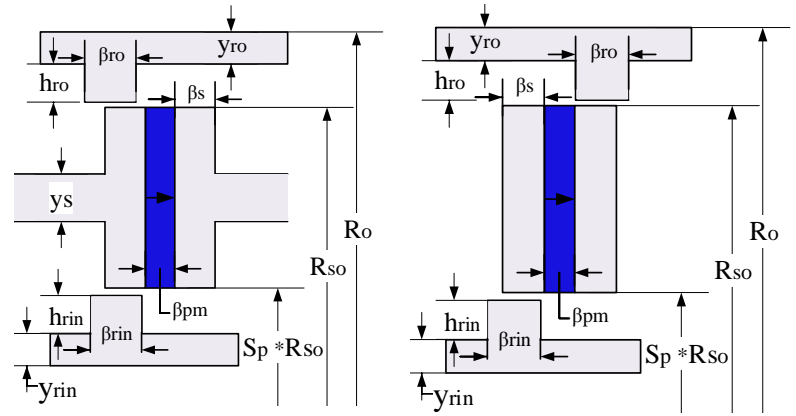

(c) PA PR-SFPM

(d) SE PR-SFPM

Fig.5 The design parameters of studied topologies

\subsection{No-Load Performance}

In this sub-section, the no-load performances for all topologies, at operating speed of $200 \mathrm{rpm}$, are investigated and compared. The comparison of no-load flux linkage is shown in Fig.6. The PA PR topology has the highest no-load flux linkage peak of $0.31 \mathrm{~Wb}$., since the magnetic flux path in the PA PR topology has the lowest total reluctance. The magnetic flux path in PA PR topology is divided into two parallel paths, hence there are two parallel reluctances, and each path has two air-gaps. On the other hand, other topologies have single flux path which passes through four air-gaps, (see Fig.3 and Fig.4). Hence, the PA PR topology has the highest flux linkage. The SE PR topology has the lowest flux linkage of $0.1 \mathrm{~Wb}$, since it has the longest flux path and the highest reluctance. The PS-SFPM topologies have nearly the same no-load flux linkages of $0.14 \mathrm{~Wb}$, as

\begin{tabular}{|c|c|c|c|c|c|}
\hline \multirow{2}{*}{ Parameter } & \multirow{2}{*}{ Symbol } & \multicolumn{4}{|c|}{ PS-SFPM PR-SFPM } \\
\hline & & Cy & SA & PA & SE \\
\hline Split ratio & $\mathrm{S}_{\mathrm{p}}$ & 0.75 & 0.74 & 0.68 & 0.37 \\
\hline Stator tooth arc (deg) & $\beta_{\mathrm{s}}{ }_{\beta_{\text {sin }}}^{\beta_{\text {so }}}$ & $\begin{array}{l}3.2 \\
-\end{array}$ & $\begin{array}{l}4.5 \\
4.5\end{array}$ & 5.4 & 3.5 \\
\hline Rotor pole arc (deg) & $\beta_{\mathrm{r}}{ }^{\beta_{\text {ro }}}$ & 7.3 & 6.8 & $\begin{array}{l}5.8 \\
6.7\end{array}$ & 4.1 \\
\hline Rotor tooth high (mm) & $\begin{array}{r}\mathrm{h}_{\mathrm{r}} \\
\mathrm{h}_{\mathrm{ro}} \\
\mathrm{h}_{\mathrm{rin}}\end{array}$ & 5.5 & 5 & $\begin{array}{l}4.3 \\
8.7\end{array}$ & $\begin{array}{l}3.7 \\
10.6\end{array}$ \\
\hline Rotor yoke thickness (mm) & $\begin{array}{l}\mathrm{y}_{\text {ro }} \\
\mathrm{y}_{\text {rin }}\end{array}$ & - & - & $\begin{array}{l}5.2 \\
5\end{array}$ & $\begin{array}{l}12 \\
12\end{array}$ \\
\hline $\begin{array}{l}\text { Stator yoke thicknes } \\
(\mathrm{mm})\end{array}$ & $\mathrm{y}_{\mathrm{s}} \mathrm{y}_{\mathrm{so}}$ & $\begin{array}{l}- \\
6.3\end{array}$ & $\begin{array}{l}8.6 \\
6.3\end{array}$ & 6.9 & - \\
\hline Number of rotor poles & $\mathrm{N}_{\mathrm{r}}$ & 31 & & & \\
\hline Number of stator poles & $\mathrm{N}_{\mathrm{s}}$ & 12 & & & \\
\hline Stack length (mm) & $\mathrm{L}_{\mathrm{a}}$ & 50 & & & \\
\hline Outer Radius(mm) & $\mathrm{R}_{\mathrm{o}}$ & 95 & & & \\
\hline Number of turns per coil & $\mathrm{N}_{\mathrm{c}}$ & 280 & & & \\
\hline Series coils per phase & $\mathrm{N}_{\mathrm{sc}}$ & 4 & & & \\
\hline Inner air-gap (mm) & $\mathrm{g}_{\text {in }}$ & 0.5 & & & \\
\hline Outer air-gap (mm) & $\mathrm{g}_{\mathrm{o}}$ & 0.5 & & & \\
\hline Current density $\left(\mathrm{A} / \mathrm{mm}^{2}\right)$ & $\mathrm{J}$ & 10 & & & \\
\hline $\mathrm{PM}$ volume $\left(\mathrm{mm}^{3}\right)$ & & 180 & $\mathrm{~nm}^{2} *$ & $0 \mathrm{~mm}$ & \\
\hline Packing factor & $\mathrm{K}_{\mathrm{pf}}$ & 0.5 & & & \\
\hline Iron type & - & M19 & $29 \mathrm{G}$ & & \\
\hline PM type & - & $\mathrm{NdF}$ & e35 & & \\
\hline
\end{tabular}
they have the same flux path.

TABLE I. Optimal Design Parameters

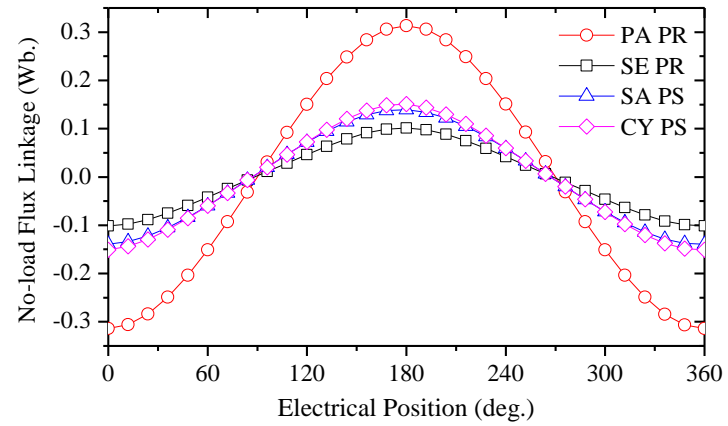

Fig.6 No-load flux linkage.

Figure 7 compares the no-load EMF, at a speed of $200 \mathrm{rpm}$, for all topologies. As expected, the no-load EMF of the PA PR topology has the highest fundamental as well as the lowest harmonic content (THD $=3.9 \%)$. In contrast, the SE PR topology has the lowest fundamental and the highest harmonic 
content $(\mathrm{THD}=12.7 \%)$, whereas the PS topologies nearly have similar fundamental and negligible odd harmonics. However, the SA PS topology has a slightly lower fundamental, and lower harmonic content $(\mathrm{THD}=6.65 \%)$, compared with the CY PS topology (THD $=11.68 \%)$, as illustrated in Fig.7 (b).

\subsection{Torque Performance and Losses}

Figure 8 compares the electromagnetic torque at a current density of $10 \mathrm{~A} / \mathrm{mm}^{2}$ and rotor speed of $200 \mathrm{rpm}$. It is clear that the PR topologies surpass the PS topologies in the electromagnetic torque. The PA PR topology has the highest average torque of 47 N.m, although it has the lowest slot area, thus draws the lowest phase current, see Fig.9. As mentioned earlier, the PA PR has lowest reluctance, hence higher flux linkage. Therefore, it provides higher average torque at lower armature current. The electromagnetic torque $\left(\mathrm{T}_{\mathrm{e}}\right)$ is given as follows;

$$
\mathrm{T}_{\mathrm{e}}=3 / 2 \mathrm{~N}_{\mathrm{r}}\left[\psi_{\mathrm{m}} \mathrm{i}_{\mathrm{q}}+\left(\mathrm{L}_{\mathrm{d}}-\mathrm{L}_{\mathrm{q}}\right) \mathrm{i}_{\mathrm{d}} \mathrm{i}_{\mathrm{q}}\right]
$$

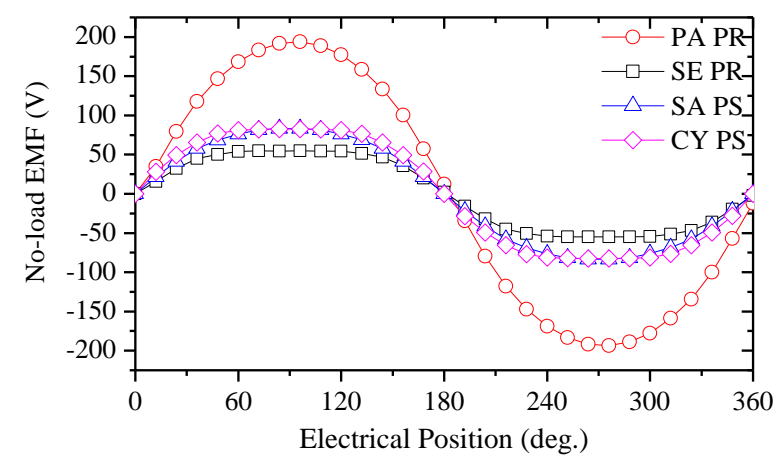

(a) Waveforms

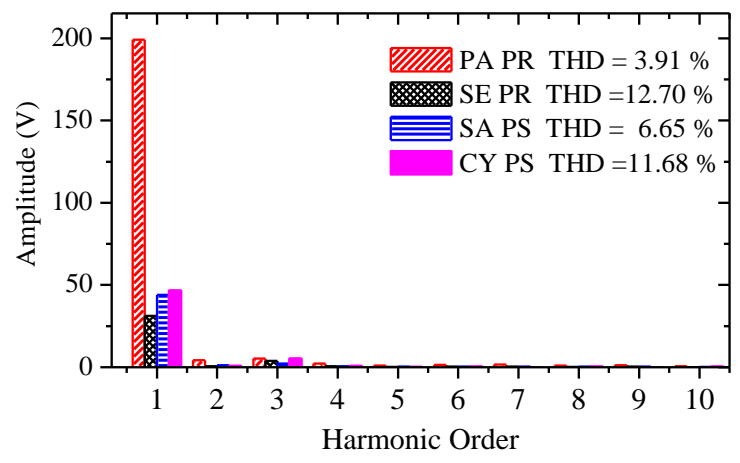

(b) Spectra

Fig.7 No-load phase EMF at 200 rpm

where $\psi_{\mathrm{m}}$ is the flux linkage, $\mathrm{i}_{\mathrm{d}}, \mathrm{i}_{\mathrm{q}}, \mathrm{L}_{\mathrm{d}}$, and $\mathrm{L}_{\mathrm{q}}$ are the $\mathrm{d}$-axis and q-axis currents and inductances, respectively. The SE PR topology provides average torque of $44 \mathrm{~N} . \mathrm{m}$ at $10 \mathrm{~A} / \mathrm{mm}^{2}$. In contrast to the PA PR topology, the SE counterpart has a larger slot area. Therefore, it draws higher phase current, see Fig. 9. However, its average output torque is lower than that of the PA PR topology, since it has lower flux linkage. The electromagnetic torque of the two PS topologies is similar. The average output torques of CY PS and SA PS are 42.5 N.m and 39.5 N.m, respectively.

In addition, the PR topologies have lower torque ripples than the PS topologies, as shown in Fig.8. The torque ripple factor is calculated as follows;

$$
\mathrm{T}_{\mathrm{rp}}=\left(\mathrm{T}_{\max }-\mathrm{T}_{\min }\right) / \mathrm{T}_{\mathrm{ave}}
$$

where $\mathrm{T}_{\max }$, and $\mathrm{T}_{\min }$ are the maximum and minimum values of the output torque. Since all topologies have the same PM volume $\left(12 \times 180 \mathrm{~mm}^{2} \times 50 \mathrm{~mm}\right)$, the PR topologies surpass the PS topologies in the PM utilization ratio. The average torque per PM volume for the PA PR and the SE PR topologies are $0.44 \mathrm{~N} . \mathrm{m} / \mathrm{cm}^{3}$ and $0.41 \mathrm{~N} . \mathrm{m} / \mathrm{cm}^{3}$, respectively. On the other side, the average torque per PM volume for the CY PS and the SA PS topologies are $0.40 \mathrm{~N} . \mathrm{m} / \mathrm{cm}^{3}$ and 0.37 $\mathrm{N} . \mathrm{m} / \mathrm{cm}^{3}$, respectively.

The average torque vs. current density characteristics for all studied topologies are shown in Fig.10. The relation between the average torque and the current density is nearly linear up to rated current density $\left(10 \mathrm{~A} / \mathrm{mm}^{2}\right)$ for all topologies. Then it becomes non-linear due to the armature reaction. It can be noticed that the SE PR topology has higher armature reaction since it has higher slot area, and higher input current.

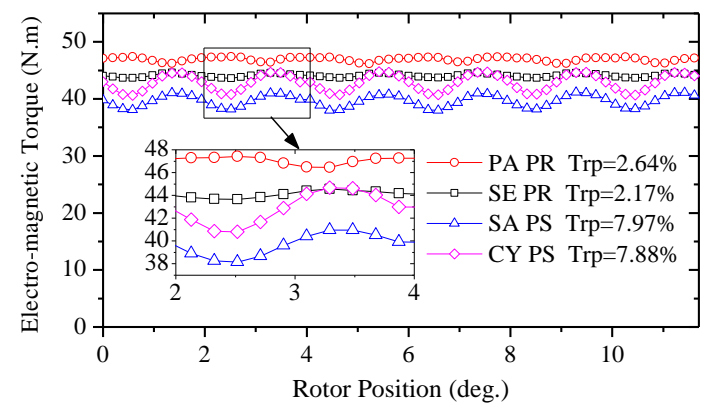

Fig.8 Electromagnetic torque at $10 \mathrm{~A} / \mathrm{mm}^{2}$

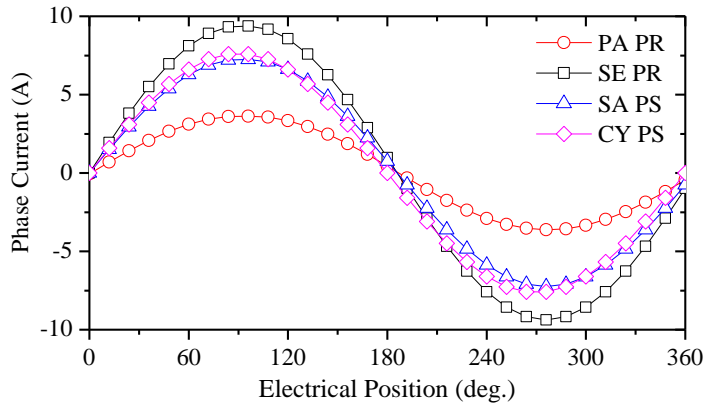

Fig.9 Phase current at $10 \mathrm{~A} / \mathrm{mm}^{2}$

The copper losses are calculated, with neglecting end effect, as follows [16];

$$
\mathrm{P}_{\mathrm{cu}}=3 \mathrm{I}_{\varnothing}{ }^{2} \mathrm{R}_{\varnothing}=\frac{6 \mathrm{I}_{\varnothing}^{2} \rho_{\mathrm{cu}} \mathrm{N}_{\mathrm{sc}} \mathrm{N}_{\mathrm{c}}{ }^{2} \mathrm{~L}_{\mathrm{a}}}{\mathrm{K}_{\mathrm{pf}} \mathrm{A}_{\mathrm{c}}}
$$

where $R_{\emptyset}$ is the phase resistance, which is given by;

$$
\mathrm{R}_{\emptyset}=\frac{2 \rho_{\mathrm{cu}} \mathrm{N}_{\mathrm{sc}} \mathrm{N}_{\mathrm{c}}{ }^{2} \mathrm{~L}_{\mathrm{a}}}{\mathrm{K}_{\mathrm{pf}} \mathrm{A}_{\mathrm{c}}}
$$

where $\rho_{\mathrm{cu}}$ is the copper resistivity, $\mathrm{N}_{\mathrm{sc}}$ is the number of coils per phase, $I_{\varnothing}$ is the input phase current, and $A_{c}$ is the slot area. The torque vs. copper loss characteristics are compared for all studied topologies as shown in Fig.11. As expected, the PA PR topology provides the highest average torque, with the same copper loss, since it has the highest PM flux linkage yet the lowest phase current. The PS topologies and the SE PR topology exhibit the same average torque-copper losses characteristic except that the SE PR topology has higher armature reaction. 


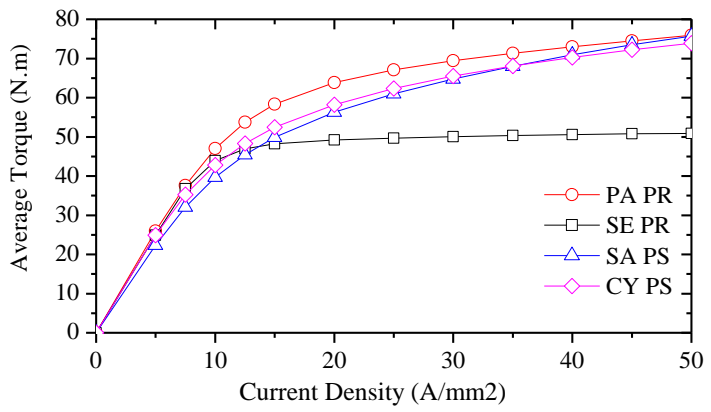

Fig.10 Average torque vs. current density

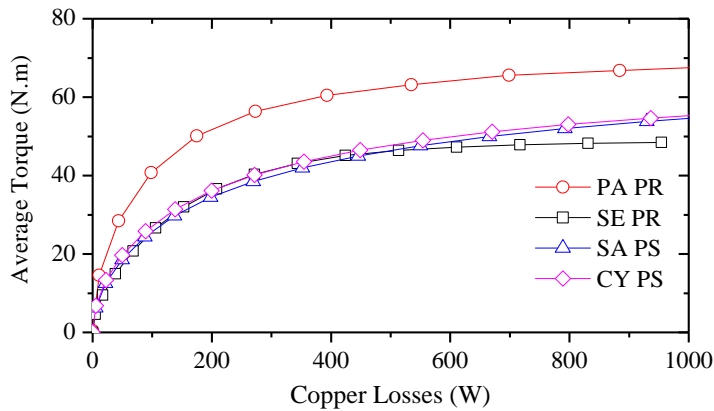

Fig.11 Average torque vs. copper loss

The torque vs. current angle characteristics are compared in Fig.12. It is clear that the maximum torque for all studied machines occurs at current angles near zero, which indicates that these topologies have a negligible reluctance torque and zero d-axis current can be used for the maximum torque per ampere control. Figure 13 compares the core loss against the rotor speed at the same current density $\left(\mathrm{J}=10 \mathrm{~A} / \mathrm{mm}^{2}\right)$. The core loss is calculated as follows;

$$
\mathrm{P}_{\text {iron }}=\mathrm{k}_{\mathrm{h}} \mathrm{fB}_{\text {max }}^{2}+\mathrm{k}_{\mathrm{c}} \mathrm{f}^{2} \mathrm{~B}_{\max }^{2}+\mathrm{k}_{\mathrm{e}} \mathrm{f}^{1.5} \mathrm{~B}_{\max }^{1.5}
$$

where $\mathrm{k}_{\mathrm{h}}=155.9 \mathrm{~W} / \mathrm{m}^{3} \quad \mathrm{k}_{\mathrm{c}}=0.119 \mathrm{~W} / \mathrm{m}^{3}, \mathrm{k}_{\mathrm{h}}=2.2 \mathrm{~W} / \mathrm{m}^{3}$ are the hysteresis, eddy current, and excess loss coefficients of the core material, respectively. $f$, and $B_{\max }$ are the operating frequency and the maximum flux density, respectively. All the studied machines have nearly the same core loss trends except the SE PR topology, it has higher core loss at each rotor speed. This is because, the SE PR topology has higher phase current at the same current density. On other words, the SE PR topology has the highest armature reaction, hence the highest armature reaction harmonics magnitude, that increases the core flux density variations [17]. Thus, the core loss of the SE PR topology is higher at each rotor speed.

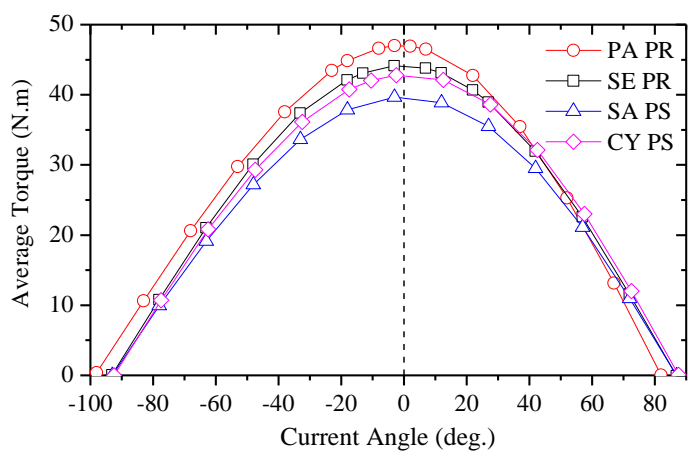

Fig.12 Torque vs. current angle

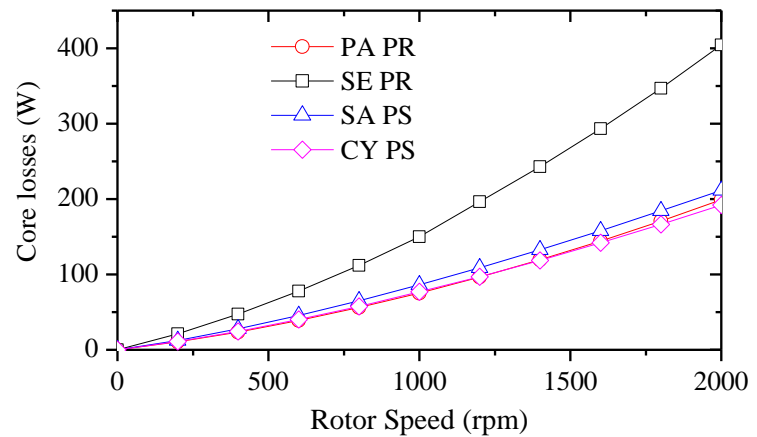

Fig.13 Core losses at $10 \mathrm{~A} / \mathrm{mm}^{2}$

\subsection{Torque-speed characteristics}

The torque-speed characteristics of electrical machines determine the speed control range for these machines, especially for electric traction and drive applications. Hence, it is important to compare the torque-speed curves for the studied topologies. Different methods are used to predict the torque-speed characteristics for electrical machines [18, 19]. In this paper the direct FE method is used to predict the torque-speed characteristic of the four studied topologies considering the inverter phase voltage limitation, which is given by;

$$
\mathrm{V}_{\max }=\frac{2}{\pi} \mathrm{V}_{\mathrm{dc}}
$$

where $\mathrm{V}_{\mathrm{dc}}=500 \mathrm{~V}$ is the dc-link voltage. In the direct FE method, the optimal values of $\mathrm{I}_{\mathrm{d}}$ and $\mathrm{I}_{\mathrm{q}}$ for maximum torque at each rotor speed, which make the phase voltage within the inverter limits, are scanned by the FE model. The torque is predicted by Eq,(5), and the phase voltage is given as follows;

$\mathrm{V}_{\mathrm{ph}}=\sqrt{\left(\mathrm{I}_{\mathrm{d}} \mathrm{R}_{\mathrm{ph}}-\omega \psi_{\mathrm{q}}\right)^{2}+\left(\mathrm{I}_{\mathrm{q}} \mathrm{R}_{\mathrm{ph}}+\omega \psi_{\mathrm{d}}\right)^{2}} \leq \mathrm{V}_{\max }$

where $\omega$ is the electrical rotating speed. This method is fully accounting for the cross coupling and the saturation effects [18].

The predicted torque-speed characteristics for the studied topologies are compared in Fig.14. All machines provide wide speed control range with constant power. Although the PA PR topology has the highest torque in the constant torque region, it has reduced torque in the flux-weakening region. This means that the PA PR topology has reduced flux-weakening capability compared with other topologies. The performance of the other three topologies in the flux-weakening region is almost the same. Also, it can be noticed that the PS topologies have the same rated speed of $270 \mathrm{rpm}$, which is higher than that of SE PR topology of $200 \mathrm{rpm}$ and higher than the PA PR topology of $174 \mathrm{rpm}$.

The power-speed characteristics are compared in Fig.15. The PS topologies have higher output power in the flux-weakening region compared with the PR topologies. The PS topologies have nearly the same power about $1320 \mathrm{~W}$ but the CY PS topology is slightly higher. The SE PR and the PA PR topologies have reduced rated power at $1150 \mathrm{~W}$ and $820 \mathrm{~W}$ respectively. 


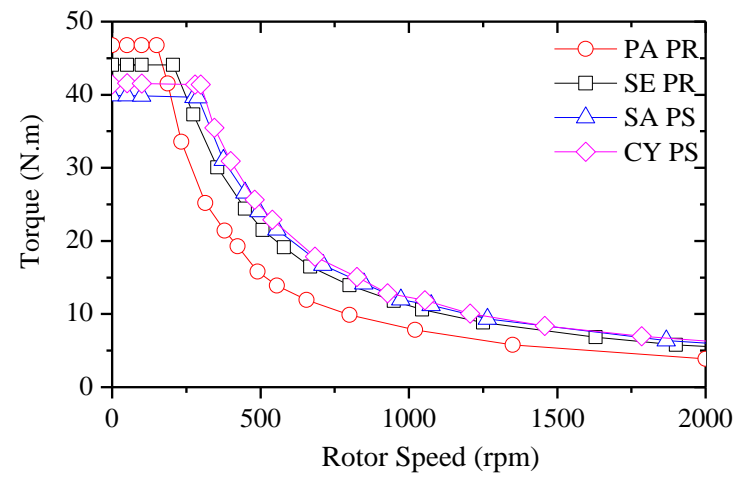

Fig.14 Torque-speed characteristics

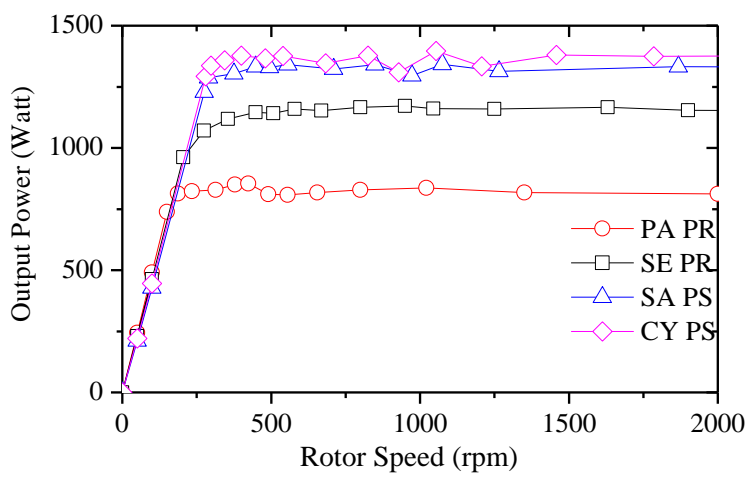

Fig.15 Power-speed characteristics

The flux-weakening capability factor is another important parameter, which describes the torque-speed performance. The flux-weakening capability factor, $\mathrm{K}_{\mathrm{fw}}$, is defined as follows [20];

$$
\mathrm{K}_{\mathrm{fw}}=\frac{\mathrm{L}_{\mathrm{d}} \mathrm{I}_{\mathrm{d}}}{\psi_{\mathrm{PM}}}
$$

Figure 16 shows the variations of the flux-weakening capability factor at different per unit d-axis current magnitudes $\left|I_{d}\right|$. All the studied topologies provide infinite speed control range since they have $\mathrm{K}_{\mathrm{fw}}$ greater than unity. The SE PR topology has the highest value of $\mathrm{K}_{\mathrm{fw}}$ at each per unit $\left|I_{d}\right|$,whereas the PA PR topology has the lowest $K_{f w}$. The variations of $\mathrm{K}_{\mathrm{fw}}$ for all PS topologies have the same trend, see Fig. 16.

The efficiency of the four studied topologies at different rotor speeds are compared in Fig.17. The efficiency is calculated for all topologies as follows;

$\eta=\frac{P_{\text {out }}}{P_{\text {in }}} \times 100 \%=\frac{P_{\text {out }}}{P_{\text {out }}+P_{\text {cu }}+P_{\text {iron }}+P_{P M}} \times 100 \%$

where $\mathrm{P}_{\mathrm{PM}}$ is $\mathrm{PM}$ eddy current loss. The efficiency of all topologies is small in the region below the rated speed, since the output power is still lower than the rated power and the copper loss is high. The efficiency in this region is increasing with the rotor speed. It can be noticed that the PA PR topology has the highest efficiency in this region, since it has the smallest copper loss. In the flux-weakening region, the efficiency of the PS topologies is nearly constant since the increase in the iron loss and PM eddy current loss are compensated by the decrease in copper loss. The efficiency of the PR topologies is decreasing with higher rotor speed, since the PR topologies have higher iron loss and PM eddy current loss at high rotor speeds. The results of the comparison study between the PS-SFPM and the PR-SFPM machines are summarized in Table. II.

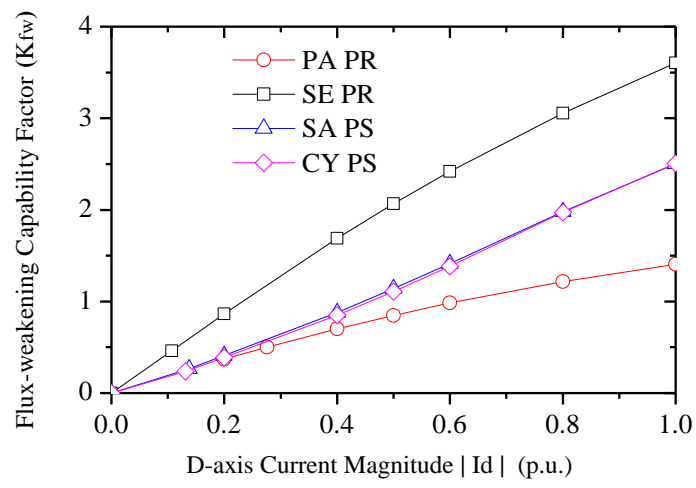

Fig.16 Flux-weakening capability vs. d-axis current

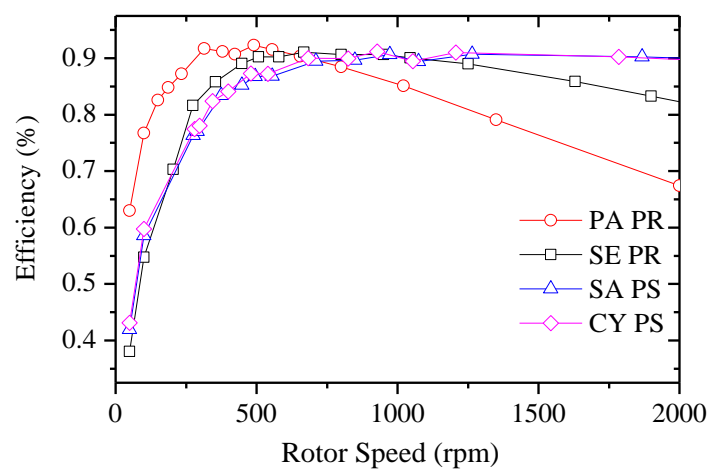

Fig.17 Efficiency

Table II. Comparison of Performance Parameters

\begin{tabular}{|c|c|c|c|c|}
\hline Performance parameters & PA PR & SE PR & SA PS & CY PS \\
\hline Peak no-load flux linkage (Wb.) & 0.31 & 0.10 & 0.14 & 0.15 \\
\hline Peak no-load $\mathrm{EMF}^{*}(\mathrm{~V})$ & 193.78 & 54.80 & 83.28 & 82.42 \\
\hline THD of no-load $\mathrm{EMF}^{*}(\%)$ & 3.91 & 12.7 & 6.65 & 11.68 \\
\hline Peak rated phase current (A) & 3.627 & 9.37 & 7.24 & 7.63 \\
\hline Rated torque (N.m) & 47 & 44 & 42.5 & 39.5 \\
\hline Torque ripples (\%) & 2.64 & 2.17 & 7.97 & 7.88 \\
\hline Torque/PM volume $\left(\mathrm{Nm} / \mathrm{cm}^{3}\right)$ & 0.435 & 0.407 & 0.394 & 0.366 \\
\hline Torque/ampere ratio (Nm/A) & 9.16 & 3.32 & 4.15 & 3.66 \\
\hline Phase resistances $(\Omega)$ & 7.3 & 2.83 & 3.67 & 3.69 \\
\hline Self-inductance $(\mathrm{H})$ & 0.14 & 0.053 & 0.059 & 0.055 \\
\hline DC link voltage (V) & 500 & & & \\
\hline Current density $\left(\mathrm{A} / \mathrm{mm}^{2}\right)$ & 10 & & & \\
\hline Rated speed (rpm) & 174 & 200 & 270 & 270 \\
\hline Rated output power (W) & 820 & 1150 & 1320 & 1350 \\
\hline Rated efficiency (\%) & 84.8 & 70.3 & 76.3 & 77.5 \\
\hline Approximate mass (Kg) & 6.84 & 8.11 & 6.69 & 8.25 \\
\hline Flux-weakening capability factor ${ }^{* *}$ & 1.4 & 3.6 & 2.51 & 2.51 \\
\hline
\end{tabular}

* Speed=200 rpm

$* * \mathrm{I}_{\mathrm{d}} \mid=1 \mathrm{pu}$. 


\section{CONCLUSIONS}

In this paper, two different topologies of PS-SFPM machines are compared with two different topologies of PR-SFPM machine. Since All studied topologies are designed with the same input parameters and optimized under the same conditions, the competition between these topologies is fair. The comparison results can be concluded as follows;

1) The PA PR topology exhibits the highest no-load flux linkage at $0.31 \mathrm{~Wb}$., and the highest no-load EMF at 193V peak with $3.91 \%$ THD.

2) The PA PR topology has the best torque performance, since it has the highest average torque, torque/ampere ratio, and torque/PM volume ratio compared with other topologies. These advantages of the PA PR topology come from the enhanced magnetic circuit permeance of this topology.

3) On the other hand, the PS topologies provide higher power density, enhanced PM cooling properties. and higher rated speed at the same dc-link voltage.

4) All studied topologies exhibit wide speed control range with constant power. The SE PR topology has the highest flux-weakening capability factor at 3.6, then the PS topologies at same value of 2.51. The PA PR topology has the lowest flux-weakening capability factor at 1.4.

Hence it can be concluded that the PS topologies are more suitable for high power density direct drive applications with wide speed control ranges, whereas the PA PR topology is more convenient in low speed direct drive applications, since it has the highest efficiency at low speeds. New improved topologies, which combine the advantages of both machines, will be investigated in future works.

\section{REFERENCES}

[1] S. Niu, S. Ho, and W. Fu, "A novel direct-drive dualstructure permanent magnet machine," IEEE Transactions on Magnetics, vol. 46, pp. 2036-2039, 2010.

[2] Z. Zhu, J. Chen, Y. Pang, D. Howe, S. Iwasaki, and R. Deodhar, "Analysis of a novel multi-tooth flux-switching PM brushless AC machine for high torque direct-drive applications," IEEE Transactions on Magnetics, vol. 44, pp. 4313-4316, 2008.

[3] S.-U. Chung, J.-M. Kim, D.-H. Koo, B.-C. Woo, D.-K. Hong, and J.-Y. Lee, "Fractional slot concentrated winding permanent magnet synchronous machine with consequent pole rotor for low speed direct drive," IEEE Transactions on Magnetics, vol. 48, pp. 2965-2968, 2012.

[4] D. J. Evans and Z. Zhu, "Novel partitioned stator switched flux permanent magnet machines," IEEE Transactions on Magnetics, vol. 51, pp. 1-14, 2015.

[5] E. E. Mohamed, D. Reigosa, and Z. Zhu, "Novel salient inner stator Partitioned Stator Switched Flux PM machine," 2016 Eighteenth International Middle East in Power Systems Conference (MEPCON), pp. 523-528, 2016.

[6] C. Awah, Z. Zhu, Z. Wu, H. Zhan, J. Shi, D. Wu, and X. $\mathrm{Ge}$, "Comparison of partitioned stator switched flux permanent magnet machines having single-or doublelayer windings," IEEE Transactions on Magnetics, vol. 52, pp. 1-10, 2016.
[7] Z. Xiang, L. Quan, and X. Zhu, "A new partitioned-rotor flux-switching permanent magnet motor with high torque density and improved magnet utilization," IEEE Transactions on Applied Superconductivity, vol. 26, pp. $1-5,2016$.

[8] D. Fan, L. Quan, X. Zhu, Z. Xiang, and W. Wu, "Electromagnetic Performance Analysis of a Partitioned Rotor Hybrid-Excited Flux-Switching Permanent Magnet Machine," 2016 IEEE in Vehicle Power and Propulsion Conference (VPPC), pp. 1-6, 2016.

[9] M. S. Saeed, E. E. Mohamed, and M. A. Sayed, "Design and analysis of dual Rotor Multi-Tooth Flux Switching machine for wind power generation," 2016 Eighteenth International Middle East in Power Systems Conference (MEPCON), pp. 499-505, 2016

[10] H. Hua and Z. Zhu, "Novel Partitioned Stator Hybrid Excited Switched Flux Machines," IEEE Transactions on Energy Conversion, 2017.

[11] Z. Zhu, Z. Wu, D. Evans, and W. Chu, "A wound field switched flux machine with field and armature windings separately wound in double stators," IEEE Transactions on Energy Conversion, vol. 30, pp. 772-783, 2015.

[12] Z. Zhu, Y. Zhou, and J. Chen, "Investigation of axial field partitioned stator switched flux machines,", 2015 Tenth International Conference on Ecological Vehicles and Renewable Energies (EVER), pp. 1-7, 2015.

[13] C. Yu and S. Niu, "Development of a magnetless flux switching machine for rooftop wind power generation," IEEE Transactions on Energy Conversion, vol. 30, pp. 1703-1711, 2015

[14] G. Pellegrino, A. Vagati, P. Guglielmi, and B. Boazzo, "Performance comparison between surface-mounted and interior PM motor drives for electric vehicle application," IEEE Transactions on Industrial Electronics, vol. 59, pp. 803-811, 2012.

[15] S. Jia, R. Qu, J. Li, X. Fan, and M. Zhang, "Study of direct-drive permanent-magnet synchronous generators with solid rotor back iron and different windings," IEEE Transactions on Industry Applications, vol. 52, pp. 13691379,2016

[16] Z. Zhu, C. C. Awah, Z. Wu, D. Wu, and X. Ge, "Electromagnetic performance of switched flux PM machines with two separate stators," COMPEL: The International Journal for Computation and Mathematics in Electrical and Electronic Engineering, vol. 35, pp. 376-395, 2016.

[17] D. Evans, Z. Zhu, Z. Wu, H. Zhan, and X. Ge, "Comparative analysis of parasitic losses in partitioned stator switched flux PM machines with double-and single-layer windings," 2015 IEEE International Electric Machines \& Drives Conference (IEMDC), pp. 167-173, 2015.

[18] G. Qi, J. Chen, Z. Zhu, D. Howe, L. Zhou, and C. Gu, "Influence of skew and cross-coupling on fluxweakening performance of permanent-magnet brushless AC machines," IEEE Transactions on Magnetics, vol. 45, pp. 2110-2117, 2009.

[19] A. Masmoudi, Z. Zhu, and Z. Azar, "Torque speed characteristics of switched flux permanent magnet machines," COMPEL-The international journal for 
computation and mathematics in electrical and electronic engineering, vol. 31, pp. 22-39, 2011.

[20] W. L. Soong and T. Miller, "Field-weakening performance of brushless synchronous AC motor drives,"
IEE Proceedings-Electric Power Applications, vol. 141, pp. 331-340, 1994 